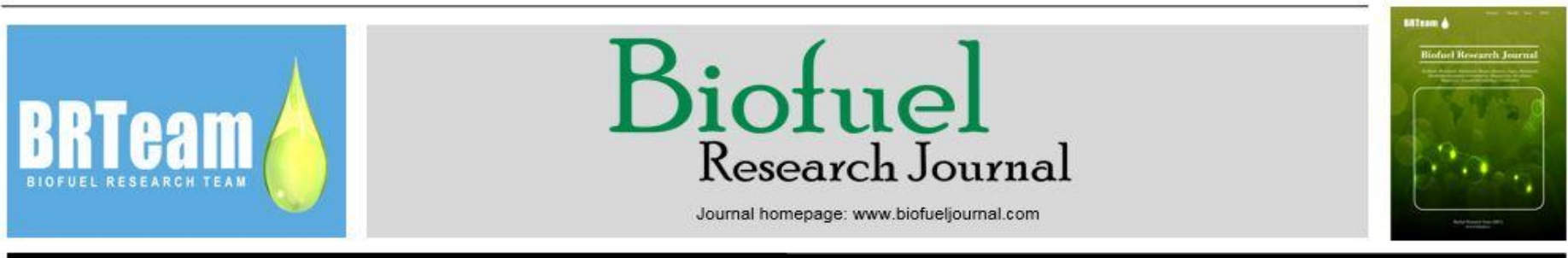

Original Research Paper

\title{
Pyrolysis characteristic of kenaf studied with separated tissues, alkali pulp, and alkali lignin
}

\author{
Yasuo Kojima ${ }^{1} *$, Yoshiaki Kato ${ }^{1}$, Minami Akazawa ${ }^{2}$, Seung-Lak Yoon ${ }^{3}$, Myong-Ku Lee ${ }^{4}$ \\ ${ }^{1}$ Department of Applied Biological Chemistry, Faculty of Agriculture, Niigata University, 2-8050 Ikarashi, Nishi-ku, Niigata, 950-2181, Japan. \\ ${ }^{2}$ Graduate School of Science and Technology, Niigata University, Niigata, 950-2181, Japan. \\ ${ }^{3}$ Department of Interior Materials Engineering, Gyeongnam National University of Science and Technology, 150 Chiram-Dong, Jinju, Gyeongnam, 660-758, \\ Korea. \\ ${ }^{4}$ Department of Paper Science \& Engineering, Kangwon National University, 192-1 hyoja 2-dong, Chuncheon, 200-701, Korea.
}

\section{HIGHLIGHTS}

$>$ Lignin and pulp prepared from kenaf were pyrolyzed to produce chemicals.

$>$ Pyrolysates from the alkali lignin of kenaf contained valuable phenols.

$>$ Pyrolysis of the alkali pulp of kenaf produced levoglucosan in high yields.

\section{GRAPHICAL ABSTRACT}

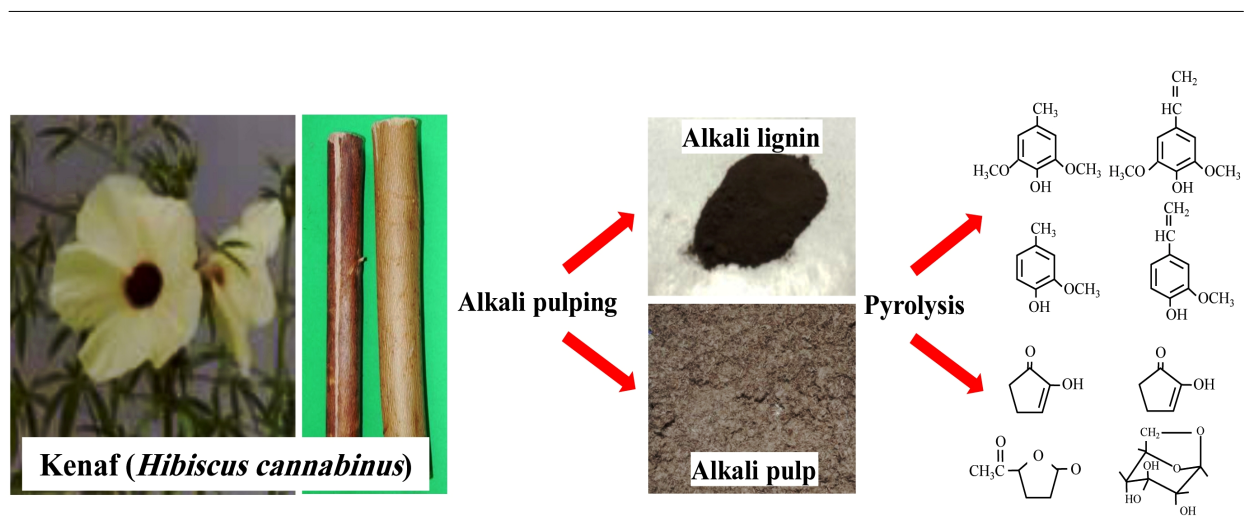

\section{ARTICLE INFO}

\section{Article history:}

Received 1 November 2015

Received in revised form 11 November 2015

Accepted 12 November 2015

Available online 1 December 2015

\section{Keywords:}

Kenaf

Analytical pyrolysis

Valuable phenols

Levoglucosan

\begin{abstract}
To estimate the potential of kenaf as a new biomass source, analytical pyrolysis was performed using various kenaf tissues, i.e., alkali lignin and alkali pulp. The distribution of the pyrolysis products from the whole kenaf was similar to that obtained from hardwood, with syringol, 4-vinylsyringol, guaiacol, and 4-vinylguaiacol as the major products. The phenols content in the pyrolysate from the kenaf core was higher than that from the kenaf cuticle, reflecting the higher lignin content of the kenaf core. The ratios of the syringyl and guaiacyl compounds in the pyrolysates from the core and cuticle samples were 2.79 and 6.83 , respectively. Levoglucosan was the major pyrolysis product obtained from the kenaf alkali pulp, although glycol aldehyde and acetol were also produced in high yields, as previously observed for other cellulosic materials. Moreover, the pathways for the formation of the major pyrolysis products from alkali lignin and alkali pulp were also described, and new pyrolysis pathways for carbohydrates have been proposed herein. The end groups of carbohydrates bearing hemiacetal groups were subjected to ring opening and then they underwent further reactions, including further thermal degradation or ring reclosing. Variation of the ring-closing position resulted in the production of different compounds, such as furans, furanones, and cyclopentenones.
\end{abstract}




\section{Introduction}

Bio-oil produced from the fast pyrolysis of biomass is considered as a new resource and a substitute for fuel oil or diesel in many static applications such as boilers, furnaces, engines, and turbines used in electricity generation and chemical production (Bridgwater, 2003). Many types of biomass have been examined for bio-oil production, and pilot plants have been established worldwide (Bridgwater and Peacocke, 2000; Zhang et al., 2007).

For instance, switch grass is considered to be a good candidate for biofuel production because of its robustness in poor soils and climatic conditions, low fertilization and herbicide requirements, and high biomass yields (McLaughlin et al., 1999). Bernhard and Joanna (2012) showed that direct combustion of switch grass led to the emission of undesirable secondary products, such as alkali, chlorine, and sulfur components, and may increase the corrosion rate of boilers. Therefore, bio-oil production as an intermediate process is important for switch grass utilization. In addition, many researchers have studied the pyrolysis conversion of switch grass and have evaluated the obtained bio-oil with respect to its chemical composition (Charles et al., 2008), energy-conversion efficiency (Boateng et al., 2007), and effect of milling (Bridgman et al., 2007). Several studies on the pyrolysis conversion of crops other than switch grass, such as wheat straw (Fidalgo et al., 1993), rice husks (Gai et al., 2013), tobacco residue (Cardoso and Ataide, 2013), orange waste (Lopez-Velazquez et al., 2013), giant cane (Temiz et al., 2013), microalgae (Wang et al., 2013), and bamboo (Kato et al., 2014), have also been reported. These plants consist of cellulose, hemicellulose, and lignin. Therefore, the bio-oil obtained from these components is a mixture of pyrolysates.

It is worth quoting that various individual components obtained from biomass have also been examined to determine their pyrolysis products. Jiang et al. (2010) investigated the effect of temperature on the composition of pyrolysis products from alcell lignin (produced from hardwood) and Asian lignin (produced from wheat straw and Sarkanda grass). They concluded that for both lignins, the maximum yield of phenolic compounds obtained at 600 ${ }^{\circ} \mathrm{C}$, was higher than that obtained directly from the whole biomass (Jiang et al., 2010). They also examined the pyrolysis kinetics of various lignin preparations and reported that the pyrolysis of alkali, hydrolytic, and organosolv lignins displayed first-order kinetics, while that of kraft lignin had 1.5-order kinetics. Analytical studies of pyrolysates obtained from isolated lignins are usually performed using pyrolysis gas chromatography mass spectrometry (Py-GC/MS), high-performance liquid chromatography (HPLC), nuclear magnetic resonance (NMR), and Fourier transform infrared spectroscopy (FT/IR). Lignin from bamboo was prepared by enzymatic/mild acidolysis followed by pyrolysis using an analytical flash pyrolyzer and gas chromatography mass spectrometry (GC/MS) (Lou et al., 2010; Lou and Wu, 2011). In a different study, Huang et al. (2012) prepared corncob acid hydrolysis residue (acid insoluble lignin) and analyzed it using thermogravimetric-FT/IR, Py-GC/MS, and scanning electron microscopy (SEM). They detected phenolic compounds which were mainly generated from the cracking of the aryl glycerol- $\beta$-ether ( $\beta-O-4)$ linkages in the samples. These phenolic compounds were suggested to be formed via multiple pathways involving further cleavage and degradation of macromolecular compounds at high temperature.

Ye et al. (2012) prepared cornstalks as a lignin model by enzymatic hydrolysis and pyrolyzed the lignin in a stainless steel autoclave reactor with various reaction (residence) times $(30-180 \mathrm{~min})$. The product distributions were analyzed by GC/MS, revealing that the increased residence times resulted in increased yields of 4-ethylphenol, 4-ethylguaiacol, and syringol and decreased yields of 2,3-dihydrobenzofuran and vinylguaiacol. Kraft lignin has also been pyrolyzed in order to estimate the optimized conditions for the production of useful bio-oil and to model the pyrolysis steps. For instance, Choi et al. (2013) reported that the pyrolysis temperature and catalyst loading level affected the yields of char, non-condensable gas, and crude bio-oil obtained from kraft. In a different investigation, Gooty et al. (2014) pyrolyzed kraft lignin in a modified bubbling bed reactor and concluded that the maximum yield of bio-oil was obtained at $550{ }^{\circ} \mathrm{C}$. Recently, Guo et al. (2015) described the pyrolysis of kraft lignin as a twostep process, proposing that the first step is governed by the Boltzmann distribution of each bond (bond cleavage), while the second step follows a Monte Carlo algorithm (radical coupling).
The pyrolysis of various carbohydrates has also been examined in order to determine the pyrolysis products obtained from biomass. Yang et al. (2006) investigated the role of three different components (cellulose, hemicellulose, and lignin) in pyrolysis using thermogravimetric analysis (TGA) and observed negligible interactions between them. By studying the product distribution obtained following the fast pyrolysis of glucosebased carbohydrates, e.g., cellulose, cellobiose, maltose, glucose, and dextran, Patwardhan et al. (2009) found that levoglucosan was the most abundant product, whose yield decreased with decreasing chain length of the carbohydrates. As a carbohydrate resource, waste paper was subjected to pyrolysis for the production of bio-oil by $\mathrm{Li}$ et al. (2005). They characterized the products by HPLC, NMR, FTIR, and UV analyses and the results achieved revealed that there were four main compounds in the produced bio-oil: anhydrosugars, carboxyl compounds, carbonyl compounds, and aromatic compounds.

Kenaf (Hibiscus cannabinus) is a plant in the Malvaceae family and is grown in many parts of the tropics, sub-tropics, and other warm areas for its bark, used as a substitute for jute in cordage and sacking. It has been cultivated for centuries in countries such as India, Bangladesh, Pakistan, China, Sudan, Cuba, Brazil, Thailand, Argentina, Italy, Russia, and Hungary (Bahtoee et al., 2012). Kenaf has a high potential biomass (22 $\left.\mathrm{t} \cdot \mathrm{ha}^{-1}\right)$, stem yield $\left(18 \mathrm{t} \cdot \mathrm{ha}^{-1}\right)$, and a high growth rate $(180-220$ $\mathrm{kg} \cdot \mathrm{ha}^{-1} \cdot \mathrm{day}^{-1}$ ) throughout the growing season. Therefore, the cuticle of kenaf, which is located on the outer parts of the shoot and is composed of long fibers, has become an important resource for fiber and paper production (Danalatos and Archontoulis, 2010). However, the inner part of the kenaf shoot, referred to as the core, cannot be used because of the characteristics of the plant tissues present in it, and thus, is considered a waste material. This material can therefore be a potential biomass source. Soda pulping of whole kenaf has been investigated, and the potential for use of the core when blended with cuticle parts (bast fiber) has been reported (Ohtani et al., 2001; Khristova et al., 2002; Hemmasi, 2012).

The aim of the present study was to estimate the potential of kenaf and its separate parts as resources for the production of bio-oil intended for use as an energy source. The mechanisms of the formation of pyrolysis products and bio-oil from the kenaf core and cuticle samples as well as from kenaf alkali lignin and alkali pulp were also investigated.

\section{Materials and methods}

\subsection{Raw materials and alkali pretreatment}

The kenaf used in this study was grown at a plantation located in Jollabuk-do, Korea. The matured kenaf was harvested $152 \mathrm{~d}$ after planting and dried at ambient temperature for more than three months. A portion of each dried kenaf plant was then debarked to separate the core and the cuticle. All samples were cut to a length of $10-15 \mathrm{~mm}$.

Alkali pulping of the kenaf samples was performed using a $10 \% \mathrm{NaOH}$ solution with a liquor ratio of 10 , a pulping temperature of $93{ }^{\circ} \mathrm{C}$, and a reaction time of $2 \mathrm{~h}$. After cooking, the alkali pulp was separated from the black liquor and washed with water. The black liquor was acidified with sulfuric acid to $\mathrm{pH} 4.0$, and then, the resultant precipitate was filtered and washed with water to obtain the alkali lignin.

\subsection{Analytical pyrolysis}

The kenaf samples were pyrolyzed using a Py-GC/flame ion detector (Py-GC/FID) consisting of an EGA/PY-3030D multi-shot pyrolyzer (Frontier Lab) and a GC-2010 Plus (Shimadzu) as well as by using a PyGC/MS consisting of a JCI-22 (JAi) Curie point pyrolyzer and a JMS T100GCV GC-TOFMS instrument (JEOL). The samples $(0.5 \mathrm{mg})$ were pyrolyzed at $590{ }^{\circ} \mathrm{C}$ using the $\mathrm{Py}-\mathrm{GC} / \mathrm{MS}$. The $\mathrm{GC}$ was equipped with an Rtx-Wax capillary column (RESTEK, $60 \mathrm{~m} \times 0.25 \mathrm{~mm}$ i.d.; $0.25 \mu \mathrm{m}$ film thickness). The injector temperature was maintained at $250{ }^{\circ} \mathrm{C}$, and split injection was performed at a $1: 100$ split rate. The column oven temperature was held at $40^{\circ} \mathrm{C}$ for $5 \mathrm{~min}$ and was then increased to $250{ }^{\circ} \mathrm{C}$ at a rate of $4{ }^{\circ} \mathrm{C} / \mathrm{min}$. An NIST mass spectral library was employed for the identification of each peak. Each peak of the chromatogram resulting from the Py-GC/FID analysis was then further identified by comparison of its retention time with that of an authentic sample (methane, methanol, acetic 
acid, furfural, 2(5H) furanone, o-guaiacol, 4-methylguaiacol, phenol, eugenol, 5-hydroxymethylfurfural, vanillin, coniferylalcohol, and levoglucosan) and by using the results of the Py-GC/MS analysis.

\section{Results and discussion}

\subsection{Physical and chemical properties of the kenaf}

Photographs of the kenaf used in the present study are shown in Figure 1. The average diameter and length of the kenaf shoots were $22 \mathrm{~mm}(16-25$

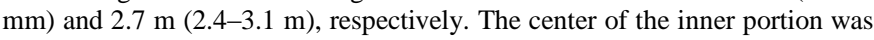
in a cavity, and the surface area (1.8-2 $\mathrm{mm})$ of the kenaf was determined by the cuticle (bast fiber). The core accounted for a large percentage of the kenaf tissues. SEM analysis revealed that the cell walls in the kenaf core are thinner than wood cell walls and, therefore, the density of kenaf is very low. In addition, the shapes of the cuticle and core are different: fibrous bundles and chip-like, respectively.

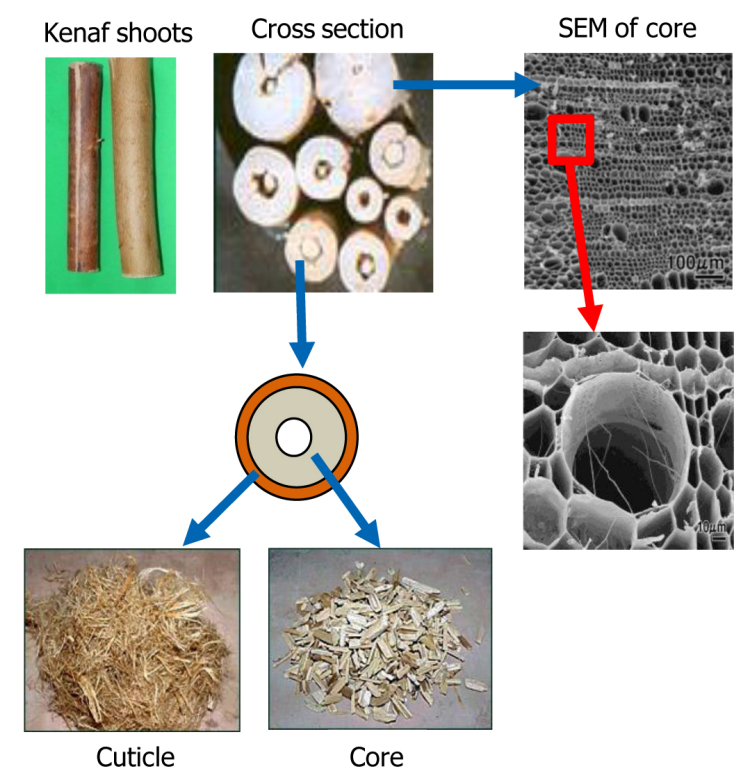

Fig.1. Shape and structure of the kenaf samples used in this study.

The proximate and chemical properties of the kenaf samples are listed in Table 1. These values are typical of lignocellulose materials without component values.

Table 1.

Proximate and chemical properties of kenaf.

\begin{tabular}{lc}
\hline (Wt.\% dry) & Content (\%) \\
\hline Proximate analysis & 80.4 \\
Volatile mater & 17.2 \\
Fixed carbon & \\
Chemical composition & 2.4 \\
Ash & 0.7 \\
$\mathrm{SiO}_{2}$ & 1.2 \\
Extractives & 81.3 \\
Holocellulose & 10.3 \\
Lignin & 42.6 \\
Cellulose & \\
Elemental composition & 44.6 \\
Carbon & 5.7 \\
Hydrogen & 0.1 \\
Nitrogen & 47.7 \\
Oxygen & 17.8 \\
Calorific value (HHV), kJ/g-dry & \\
\hline
\end{tabular}

The lignin and higher holocellulose contents in kenaf are lower than those in woody materials. These results are similar to those that have been previously reported (Bassam, 2010; Hemmasi, 2012). Khristova et al (2002) found that the lignin contents in kenaf cores and cuticles were $19.6 \%$ and $8.1 \%$, respectively. Ohtani et al. (2001) also obtained similar results. These combined results suggest that the physical and chemical properties of the core and cuticle of kenaf are significantly different.

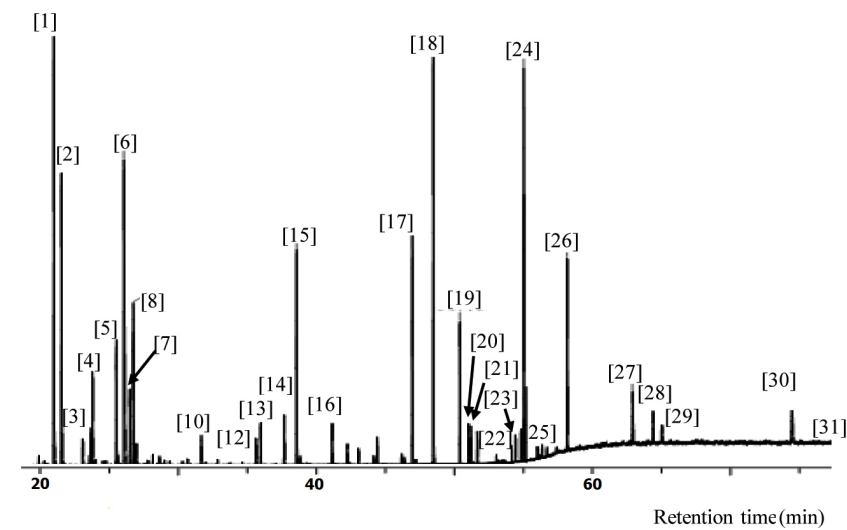

Fig.2. TIC of the py-GC/MS from whole kenaf.

\subsection{Pyrolysis of whole kenaf}

The total ion chromatography (TIC) images of the Py-GC/MS of the whole kenaf is shown in Figure 2. Thirty-one compounds were identified as pyrolysis products from the whole kenaf as listed Table 2. Guaiacol [Table 2; peak No. 15] and 4-vinyl guaiacol [peak No. 17] were detected as major products from the guaiacyl unit of kenaf lignin, while syringol [peak No.18], 4-methylsyringol [peak No. 19], 4-vinylsyringol [peak No. 24], and 4-(1-propenyl)-syringol [peak No. 26] were major products obtained from the syringyl unit of kenaf lignin.

Table 2.

Yield (\%) of pyrolysates from whole, core and cuticle of kenaf.

\begin{tabular}{|c|c|c|c|c|c|}
\hline $\begin{array}{l}\text { Peak } \\
\text { No. }\end{array}$ & R.T. & Product & Whole & Core & Cuticle \\
\hline 1 & 21.0 & Acetol & 9.71 & 8.24 & 14.99 \\
\hline 2 & 21.6 & Glycolaldehyde & 7.87 & 8.60 & 9.30 \\
\hline 3 & 23.8 & 1-Hydroxy-2-butanone & 1.22 & 0.55 & 1.20 \\
\hline 4 & 24.0 & 1-Hydroxy-3-propanal & 1.56 & 1.83 & 1.91 \\
\hline 5 & 25.7 & Butanedial & 1.97 & 2.92 & 2.28 \\
\hline 6 & 26.1 & Acetic acid & 9.26 & 8.16 & 10.50 \\
\hline 7 & 26.7 & Methyl pyruvate & 1.84 & 1.77 & 2.90 \\
\hline 8 & 27.0 & Furfural & 2.73 & 2.31 & 3.29 \\
\hline 9 & 29.2 & Propionic acid & 0.61 & 0.31 & 0.53 \\
\hline 10 & 31.9 & Ethanediol & 1.72 & 1.10 & 2.59 \\
\hline 11 & 33.0 & Furfuryl alcohol & 0.18 & - & 0.49 \\
\hline 12 & 35.9 & $2(5 \mathrm{H})$-Furanone & 0.80 & 1.12 & 1.13 \\
\hline 13 & 36.2 & 2-Hydroxy-2-cyclopenten-1-on & 1.66 & 0.76 & 1.36 \\
\hline 14 & 37.9 & 2-Hydroxy-4-methyl-2-cyclopenten-1-on & 1.88 & 0.74 & 2.00 \\
\hline 15 & 38.8 & Guaiacol & 3.44 & 2.58 & 0.53 \\
\hline 16 & 41.3 & 4-Methylguaiacol & 0.73 & 0.38 & - \\
\hline 17 & 47.2 & 4-Vinylguaiacol & 4.56 & 4.51 & 0.60 \\
\hline 18 & 48.7 & Syringol & 8.22 & 9.84 & 4.27 \\
\hline 19 & 50.6 & 4-Methylsyringol & 3.95 & 4.18 & 1.04 \\
\hline 20 & 51.4 & 4-Vinylphenol & 1.07 & 3.29 & - \\
\hline 21 & 51.8 & 4-Ethylsyringol & 0.76 & 0.69 & 0.71 \\
\hline 22 & 54.6 & (E)-4-(2-Propenyl) syringol & 0.99 & 1.03 & 0.49 \\
\hline 23 & 54.9 & Vanillin & 0.62 & 0.80 & - \\
\hline 24 & 55.0 & 4-Vinylsyringol & 7.76 & 7.99 & 3.37 \\
\hline 25 & 56.9 & Guaiacyl-2-propanone & - & 0.44 & - \\
\hline 26 & 58.2 & (E)-4-(1-Propenyl) syringol & 4.82 & 4.34 & 2.97 \\
\hline 27 & 62.9 & Syringaldehyde & 1.81 & 1.69 & 0.80 \\
\hline 28 & 64.4 & Acetosyringon & 1.06 & 0.79 & - \\
\hline 29 & 65.0 & Syringyl-2-propanone & 3.53 & 1.03 & - \\
\hline 30 & 74.5 & Coniferylalcohol & 2.17 & 4.17 & - \\
\hline 31 & 78.0 & Levoglucosan & 2.21 & 1.78 & 5.34 \\
\hline
\end{tabular}


In general, syringyl products were the dominant compounds observed in the pyrolysates obtained following whole kenaf pyrolysis, indicating that kenaf lignin is composed mainly of syringyl units. Along with low-molecularweight aliphatic compounds, furfural [peak No. 8], furfuryl alcohol [peak No. 11], furanone [peak No. 12], cyclopentanone derivatives [peak No. 13 and 14], and levoglucosan [peak No. 31], which were derived from carbohydrates, were also detected in the pyrolysate of the whole kenaf.

\subsection{Pyrolysis of separated core and cuticle kenaf tissues}

The TICs of the Py-GC/MS of the core and cuticle kenaf samples are shown in Figure 3. Twenty-eight products from the kenaf core and 22 products from the kenaf cuticle were identified. It can be seen that the TIC for the Py-GC/MS of the core was similar to that of the whole kenaf. This result is not surprising since the core has been reported to account for $78-82 \%$ of the dry weight of the kenaf stem (Gutiérrez et al., 2014).
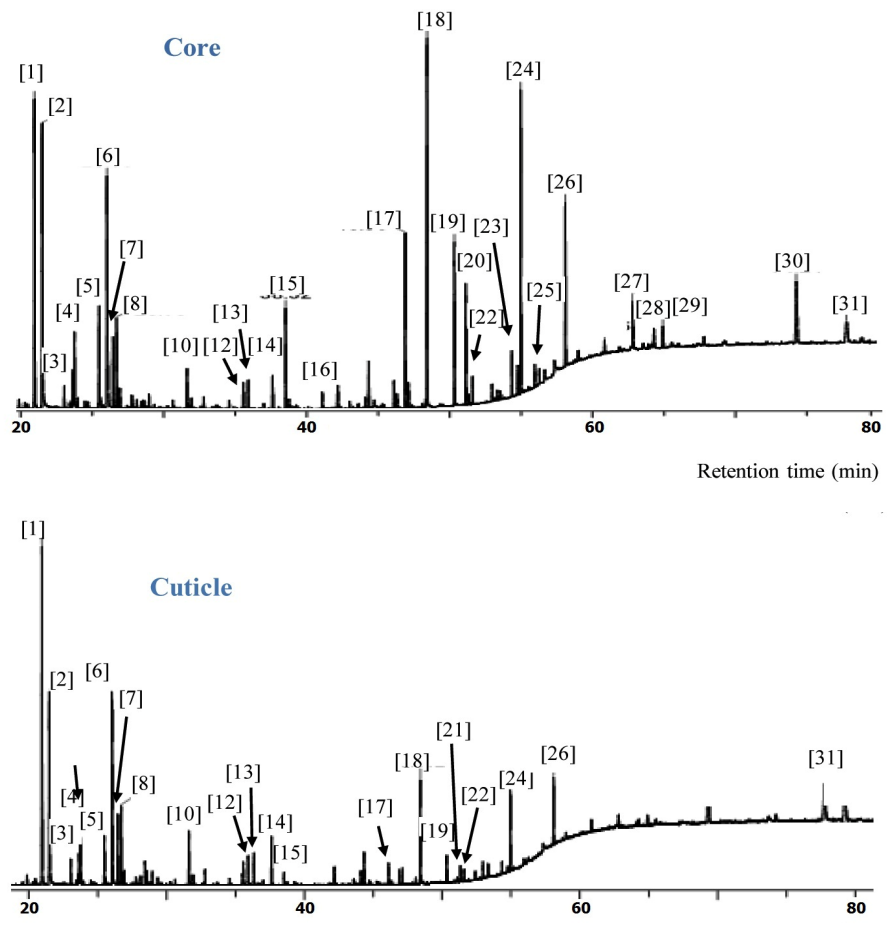

Retention time(min)

Fig.3. TIC of the py-GC/MS from kenaf's core and cuticle.

On the other hand, the TIC profile of the cuticle tissue was different from the TIC profiles of the whole kenaf and core. The peak area percentages for the major products obtained following the pyrolysis of whole kenaf, the core, and the cuticle are listed in Table 2. Following kenaf core pyrolysis, syringyl compounds such as syringol [Table 2; peak No. 18], vinyl syringol [peak No. 24], (E)-4-(1-propenyl) syringol [peak No. 26], 4-methylsyringol [peak No. 19], and syringaldehyde [peak No. 27] were identified as the major products. Some guaiacyl compounds including vinyl guaiacol [peak No. 17], guaiacol [peak No. 15], coniferyl alcohol [peak No. 30], and guaiacyl-2-propanone [peak No. 25] were also identified. Vinyl phenol [peak No. 20], a product derived from p-hydroxyl compounds, was also identified as a minor product. All these products were generated during the pyrolysis of the lignin fraction in the kenaf core tissue. Low-molecular-weight aliphatic compounds, including acetol, glycol aldehyde, and acetic acid, were identified as major pyrolysis products derived from carbohydrates.

Pyrolysis of the kenaf cuticle provided syringol [peak No. 18], vinyl syringol [peak No. 24], and syringyl propenes [peak No. 22 and 26], as well as guaiacol. The yields of these phenols were lower than those obtained from the kenaf core. Hemmasi (2012) reported that the lignin content in kenaf cuticles was lower than that in kenaf cores at $11.5 \%$ and $18.9 \%$, respectively. Therefore, the low yields of phenols in the pyrolysates from kenaf cuticle samples investigated in the present study are not surprising. On the other hand, aliphatic low-molecular-weight products were obtained in high yields. Seca et al. (1998) analyzed kenaf cores and cuticles using various methods and reported that there were strong structural differences in the bark (cuticle) and core lignins in kenaf. Nishimura et al. (2002) also analyzed separated kenaf bast, inner bast, and core samples prepared from the top, upper middle, lower middle, and bottom of kenaf stems. Their results indicated that both the lignin content and molar ratio of tota syringyl to total vanillyl (S/V) ratio varied according to the position in the kenaf stem.

Table 3.

Chemical components (\%) of kenaf's core and cuticle (Jin et. al. 2006).

\begin{tabular}{llllllll}
\hline & & Extractives & Klason & Glucose & Xylose & Arabinose & S/V ratio \\
\hline \multirow{2}{*}{ Cuticle } & Upper & 8.9 & 9.1 & 42.6 & 6.8 & 2.7 & 5.7 \\
& Lower & 6.2 & 11.7 & 42.7 & 6.5 & 3.3 & 5.0 \\
\hline \multirow{2}{*}{ Core } & Upper & 7.9 & 11.4 & 50.7 & 7.6 & 1.1 & 1.5 \\
& Lower & 7.4 & 22.1 & 40.3 & 14.3 & 0.1 & 3.2 \\
\hline
\end{tabular}

Jin et al. (2006) analyzed the bast (cuticle) and core tissues from kenaf (H. cannabinus) and reported that the cuticle tissue had a high lignin content and a high S/V ratio, as shown in Table 3. Gutierrez et al. (2004) also reported that the $\mathrm{S} / \mathrm{V}$ ratio of kenaf fiber (cuticle) was as high as 5.4. In the present study, the molar ratios of syringyl to guaiacyl (S/G) were calculated using the ratios of the peak percentages for syringol/guaiacol and vinylsyringol/vinylguaiacol. The results are tabulated in Table 4 . The S/G ratios of the cuticle and core were 8.54 and 3.81 , respectively, as determined by using the TIC peak percentages for syringol and guaiacol, while they stood at 5.62 and 1.77 , respectively, using the TIC peak percentages for vinylsyringol and vinylguaiacol. These data combined resulted in average values for the $\mathrm{S} / \mathrm{G}$ ratios of 6.83 for the cuticle and 2.79 for the core.

Table 4.

Syringyl and guaiacyl ratio $(\mathrm{S} / \mathrm{G})$ calculated based on the corresponding products from cuticle of kenaf.

\begin{tabular}{llll}
\hline & Syringol/Guaiacol & Vinylsyringol/Vinylguaiacol & Average of S/G \\
\hline Cuticle & 8.54 & 5.62 & 6.83 \\
Core & 3.81 & 1.77 & 2.79 \\
\hline
\end{tabular}

\subsection{Pyrolysis of kenaf alkali lignin and alkali pulp obtained from whole} kenaf

The TIC image of the Py-GC/MS of the kenaf alkali lignin is shown in Figure 4. Sixteen compounds were identified as pyrolysis products, including four additional products not obtained directly from the whole kenaf or its parts: phenol, 2-methycatechol, acetoguaiacone, and catechol. The structures of these chemicals are illustrated next to their peaks in Figure 4.

The TIC of the Py-GC/MS of the kenaf alkali pulp is shown in Figure 5. As presented, eighteen compounds were identified as pyrolysis products derived from carbohydrates, and once again, four additional products not detected for the other samples were observed: 5acetyldihydro-2-furanone, 3-hydroxy-butyrolactone, 3-hydroxy-5-methyl2-furanone, and 5-hydroxymethyl furfural. Notably, levoglucosan [Table 2; peak No. 31] was detected as one of the major products obtained from the pyrolysis of alkali pulp. It has been previously demonstrated that the fast pyrolysis of cellulosic materials resulted in the production of levoglucosan as a major product (Ronsee et al., 2012; Shra'ah et al., 2014).

The peak areas of the pyrolysis products obtained from the alkali lignin and alkali pulp are listed in Table 5 and compared with the pyrolysates 


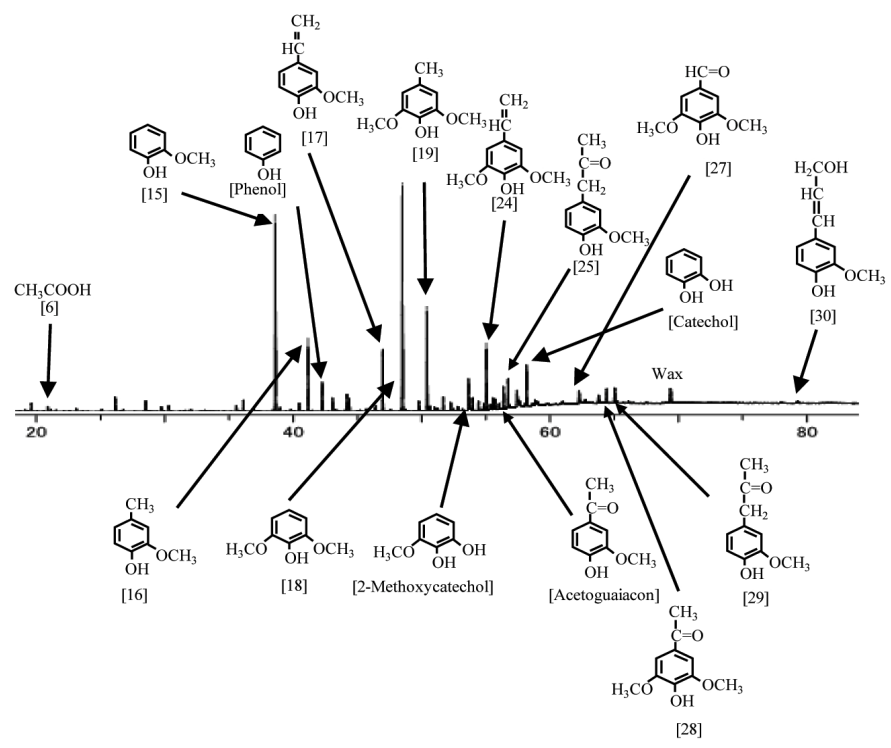

Fig.4. TIC of the py-GC/MS alkali lignin from kenaf.

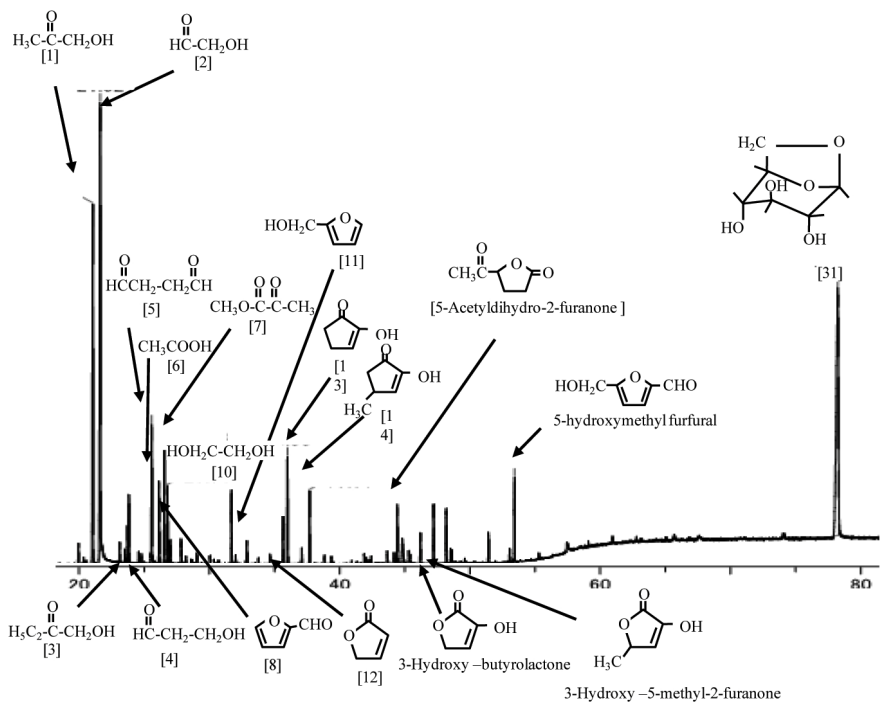

Fig.5. TIC of the py-GC/MS alkali pulp from kenaf.

obtained from the whole kenaf. Alkali lignin pyrolysis resulted in the production of typical phenol compounds in high yields, and the ratio of syringyl and guaiacyl compounds in the pyrolysate was 1.10 . This result indicated that some syringyl lignin in the kenaf tissues degraded to lowmolecular-weight compounds, which were not recovered from the black liquor as alkali lignin. In addition, the yields of guaiacol, syringol, 4methylguaiacol, and 4-methylsyringol obtained from the alkali lignin were remarkably increased compared to those obtained from the pyrolysis of the whole kenaf. This result suggested that aryl ether linkages, which are the major linkages in lignin, were cleaved, leading to an increase in the content of phenolic hydroxyl groups in the alkali lignin. As a result, electron-transfer reactions from the $\alpha$-hydroxyl groups of these compounds and via quinone methide intermediates were accelerated, as shown in Figure 6.

The pathways for the formation of cyclic monomers, such as furans, anhydrous sugars, and cyclopentanones, from carbohydrate polymers are as yet unknown, but the pathways for the formation of low-molecular-weight products from glucose have been reported in detail by Vinu et al. (2012). The pyrolysis products obtained from the alkali pulp were formed via more
Table 5.

Yield (\%) of pyrolysates from alkali lignin and alkali pulp from kenaf.

\begin{tabular}{|c|c|c|c|c|c|}
\hline $\begin{array}{l}\text { Peak } \\
\text { No. }\end{array}$ & R.T. & Product & Whole & $\begin{array}{l}\text { Alkali } \\
\text { lignin }\end{array}$ & $\begin{array}{c}\text { Alkal } \\
\text { pulp }\end{array}$ \\
\hline 1 & 21.0 & Acetol & 9.71 & - & 11.80 \\
\hline 2 & 21.6 & Glycolaldehyde & 7.87 & - & 19.02 \\
\hline 3 & 23.8 & 1-Hydroxy-2-butanone & 1.22 & & 0.94 \\
\hline 4 & 24.0 & 1-Hydroxy-3-propanal & 1.56 & - & 1.73 \\
\hline 5 & 25.7 & Butanedial & 1.97 & - & 4.17 \\
\hline 6 & 26.1 & Acetic acid & 9.26 & - & 2.69 \\
\hline 7 & 26.7 & Methyl pyruvate & 1.84 & 1.57 & 3.16 \\
\hline 8 & 27.0 & Furfural & 2.73 & - & 2.10 \\
\hline 9 & 29.2 & Propionic acid & 0.61 & - & - \\
\hline 10 & 31.9 & Ethanediol & 1.72 & - & 2.36 \\
\hline 11 & 33.0 & Furfuryl alcohol & 0.18 & - & - \\
\hline 12 & 35.9 & 2(5H)-Furanone & 0.80 & - & 1.42 \\
\hline 13 & 36.2 & 2-Hydroxy-2-cyclopenten-1-on & 1.66 & - & 3.20 \\
\hline 14 & 37.9 & 2-Hydroxy-4-methyl-2-cyclopenten-1-on & 1.88 & - & 1.81 \\
\hline 15 & 38.8 & Guaiacol & 3.44 & 17.65 & - \\
\hline 16 & 41.3 & 4-Methylguaiacol & 0.73 & 5.66 & - \\
\hline 17 & 47.2 & 4-Vinylguaiacol & 4.56 & 5.62 & - \\
\hline 18 & 48.7 & Syringol & 8.22 & 21.67 & - \\
\hline 19 & 50.6 & 4-Methylsyringol & 3.95 & 9.10 & - \\
\hline 20 & 51.4 & 4-Vinylphenol & 1.07 & - & - \\
\hline 21 & 51.8 & 4-Ethylsyringol & 0.76 & - & - \\
\hline 22 & 54.6 & (E)-4-(2-Propenyl) syringol & 0.99 & - & - \\
\hline 23 & 54.9 & Vanillin & 0.80 & - & - \\
\hline 24 & 55.0 & 4-Vinylsyringol & 7.76 & 5.47 & - \\
\hline 25 & 56.9 & Guaiacyl-2-propanone & - & 2.74 & - \\
\hline 26 & 58.2 & (E)-4-(1-Propenyl) syringol & 4.82 & 3.78 & - \\
\hline 27 & 62.9 & Syringaldehyde & 1.81 & - & - \\
\hline 28 & 64.4 & Acetosyringon & 1.06 & 1.99 & - \\
\hline 29 & 65.0 & Syringyl-2-propanone & 3.53 & 2.08 & - \\
\hline 30 & 74.5 & Coniferylalcohol & 2.17 & - & - \\
\hline 31 & 78.0 & Levoglucosan & 2.21 & - & 29.53 \\
\hline
\end{tabular}

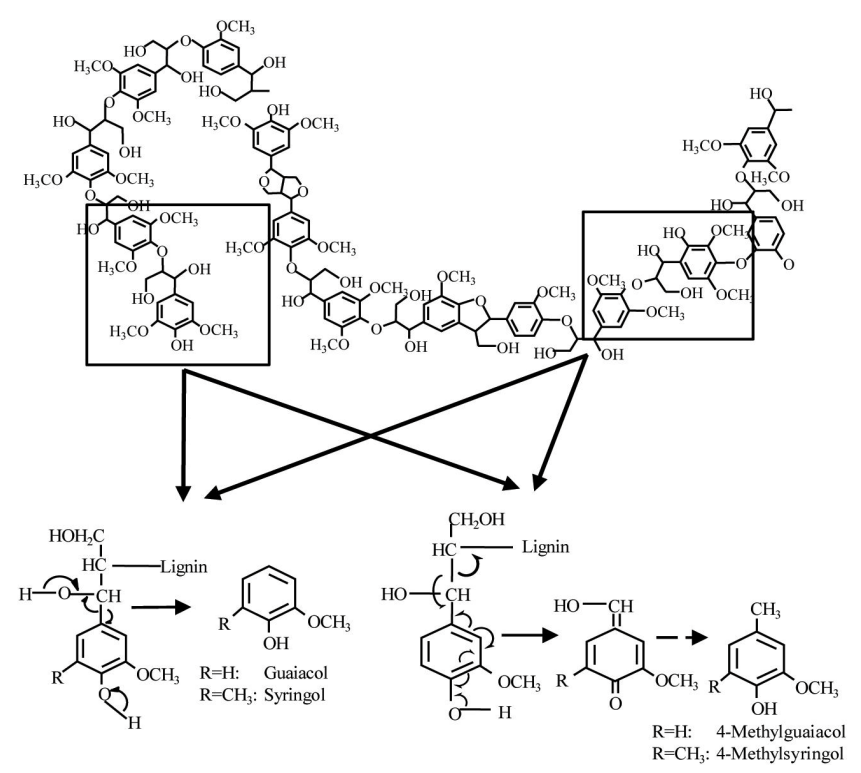

Fig.6. Proposed formation pathway of abundant pyrolysis products from lignin polymer.

complex pathways, and the proposed mechanisms are illustrated in Figures 7-9. The formation of levoglucosan [peak No. 31], which is a heterocyclic compound or anhydrosugar, is initiated by radical cleavage of a glycoside bond in an intermolecular sugar residue. The $\mathrm{C} 1$ radical then couples with a $\mathrm{C} 6-\mathrm{O}$ radical to form a new ring structure. This 


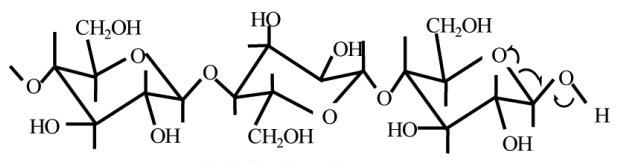

[Cellulose]

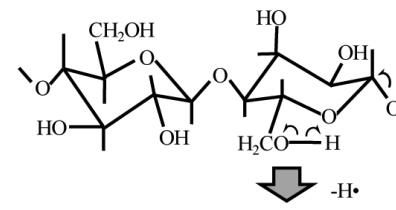

ए -
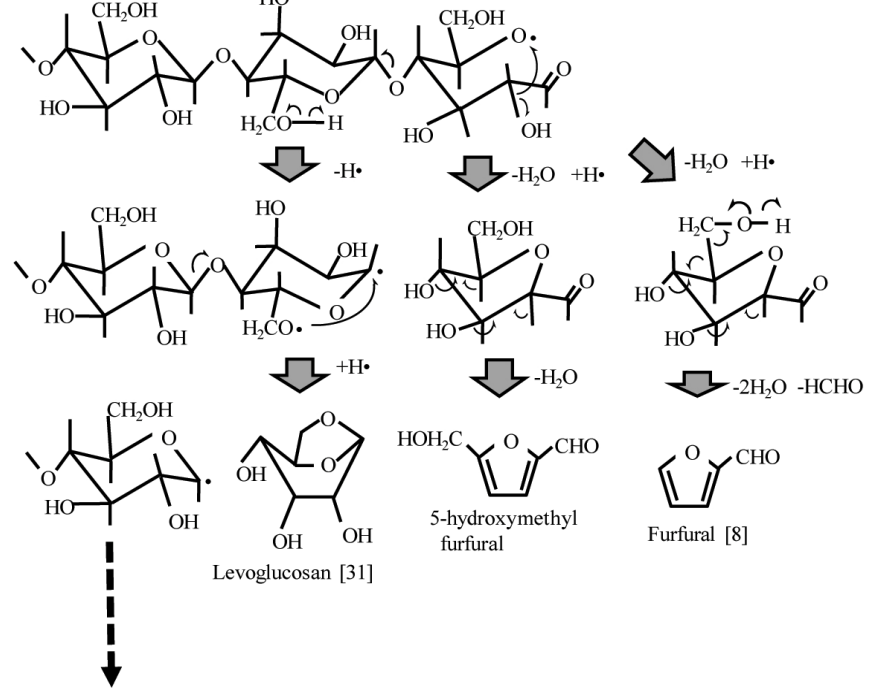

${ }^{\mathrm{HOH}_{2} \mathrm{C}} Y^{\mathrm{O}} Y^{\mathrm{CHO}}$
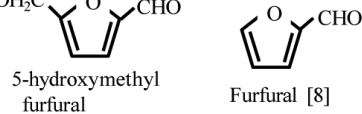

furfural

Fig.7. Proposed formation pathway of levoglucosan, 5-hydroxymethy-furfural, and furfural from alkali pulp.
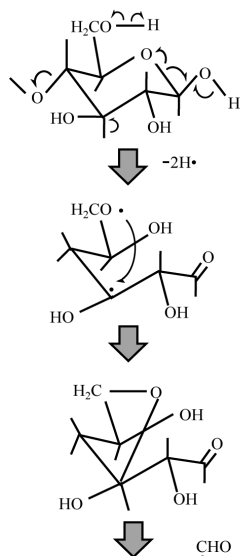<smiles>CC(O)(CO)C1(O)OC(C)(C)C(C)(O)C1(C)O</smiles><smiles>CC1(C)OC(=O)C2(C)CC1C(O)C2(O)CO</smiles>

3-Hydroxy-butyrolactone

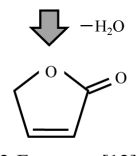

2-Furanone [12]
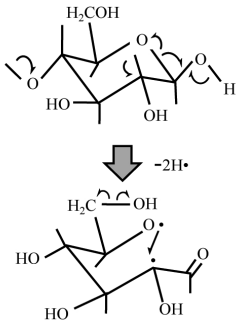

\- $-\mathrm{HO} \cdot+\mathrm{H} \cdot$

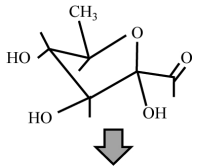<smiles>CC(=O)OC12OC(C)(C)C(O)(CC1(C)O)C2(C)C</smiles>

\- $\mathrm{HCHO}$
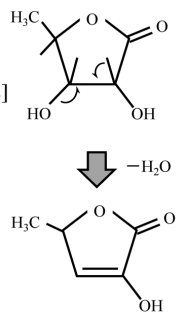

3-Hydroxy-5-methyl-2-furanone
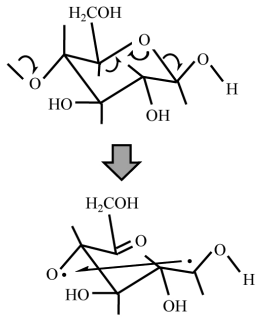

$\zeta$
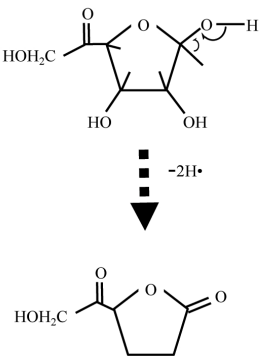

5-Acetyldihydro-2-furanone

Fig.8. Proposed formation pathway of lactone and furanones from alkali pulp.

radical is then propagated as a chain reaction in carbohydrate molecules. End groups of carbohydrates with hemiacetal groups are subjected to ring opening and further react, undergoing thermal degradation or ring reclosing. Variation of the ring-closing position yields a range of compounds, including furans, furanones, and cyclopentenones. The formation of furfurals is initiated by ring opening at the hemiacetal site, followed by coupling of the $\mathrm{C} 2$ radical with a $\mathrm{C} 5-\mathrm{O}$ radical. Dehydration then results in the formation of 5-hydroxymethyl-furfural and subsequent elimination of the C6 hydroxymethyl group as formaldehyde generates furfural, as shown in Figure 7.

The formation of 2-furanone [peak No. 12] occurs via ring opening followed by coupling of the $\mathrm{C} 3$ and $\mathrm{C} 6-\mathrm{O}$ radicals, while 2-hydroxy-5methyl-2-furanone is formed by the coupling of the $\mathrm{C} 2$ and $\mathrm{C} 5$-O radicals after ring opening, and 5-acetyldihydro-2-furanone is produced via the coupling of the $\mathrm{C} 1$ and $\mathrm{C} 4-\mathrm{O}$ radicals, followed by the donation of an $\mathrm{H}$ radical from the $\mathrm{C} 1-\mathrm{OH}$ group, as shown in Figure 8 .

Hypothetical pathways for the formation of cyclopentenones are illustrated in Figure 9. The end sugar residue of carbohydrates is subjected to ring opening, followed by coupling of the $\mathrm{C} 1$ and $\mathrm{C} 5$ radicals to form a cyclopentane structure. Hydroxyl radical elimination from the C6 hydroxymethyl group of this cyclopentane intermediate is accompanied by the elimination of formaldehyde, yields 2-hydroxy-4methyl-2 cyclopenten-1-one [peak No. 14]. The elimination of two molecules of formaldehyde at the $\mathrm{C} 1$ and $\mathrm{C} 6$ positions results in the production 2-hydroxy-2-cyclopenten-1-one [peak No. 13].
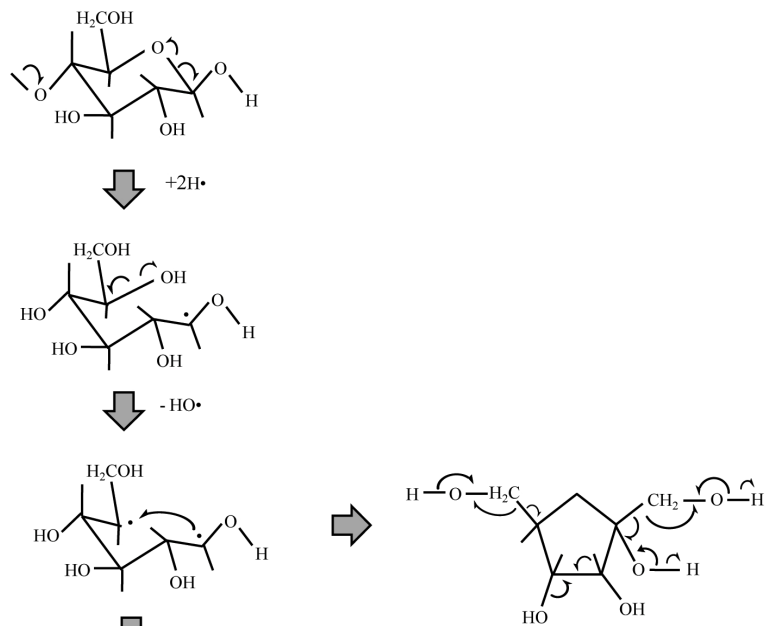

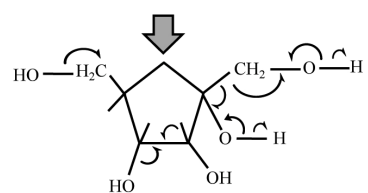
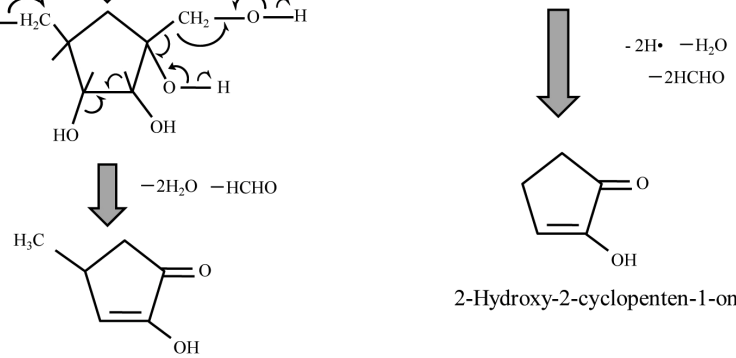<smiles>O=C1CCC=C1O</smiles>

2-Hydroxy-2-cyclopenten-1-on [13]

2-Hydroxy-4-methyl-2-cyclopenten-1-on [14]

Fig.9. Proposed formation pathway of cyclopentenones from alkali pulp.

\section{Conclusions}

The distribution of pyrolysis products obtained from the whole kenaf was found similar to that from hardwood, with syringol, 4-vinylsyringol, guaiacol, and 4-vinylguaiacol as major products. The phenols content of the pyrolysate from the kenaf core was higher than that of the kenaf cuticle, reflecting its higher lignin content. The ratios of syringyl and 
guaiacyl compounds in the pyrolysates from the core and cuticle were measured at 2.79 and 6.83 , respectively. Levoglucosan was the major pyrolysis product obtained from the kenaf alkali pulp, but glycol aldehyde and acetol were also formed in high yields. Notably, many pyrolysis products were detected that have the potential to be converted into more useful chemicals. Pathways for the formation of the major pyrolysis products from the alkali lignin and alkali pulp were presented along with newly-proposed pyrolysis pathways for carbohydrates.

\section{References}

[1] Bahtoee, A., Zargari, K., Baniani, E., 2012. An investigation on fiber production of different kenaf. World Appl. Sci. J. 16, 63-66.

[2] Bassam, E.L.N., 2010. Handbook of Bioenergy Crops: a complete reference to species, development and applications. Earthscan Ltd., Dunstan House, ISBN 978-1-84407-854-7 London.

[3] Bernhard, P., Joanna, S.O., 2012. Simultaneous prediction of potassium chloride and sulphur dioxide emissions during combustion of switchgrass. Fuel. 96, 29-42.

[4] Boateng, A.A., Daugaard, D.E., Goldberg, N.M., Hicks, K.B., 2007. Bench-scale fluidized-bed pyrolysis of switchgrass for bio-oil production. Ind. Eng. Chem. Res. 46, 1891-1897.

[5] Bridgeman, T.G., Darvell, L.I., Jones, J.M., Williams, P.T., Fahmi, R., Bridgwater, A.V., Barraclough, T., Shield, I., Yates, N., Thain, S.C., Donnison, I.S., 2007. Influence of particle size on the analytical and chemical properties of two energy crops. Fuel. 6, 60-72.

[6] Bridgwater, A.V., 2003. Renewable fuels and chemicals by thermal processing of biomass. Chem. Eng. J. 91, 87-102.

[7] Bridgwater, A.V., Peacocke, G.V.C., 2000. Fast pyrolysis processes for biomass. Renew. Sust. Energy Rev. 4, 1-73.

[8] Cardoso, C.R., Ataide, C.H., 2013. Analytical pyrolysis of tobacco residue: Effect of temperature and inorganic additives. J. Anal. Appl. Pyrol. 99, 49-57.

[9] Charles, A, Mullen, CA, Boateng, AA., 2008. Chemical composition of bio-oils produced by pyrolysis of two energy crops. Energy Fuels. 22, 2104-2109.

[10] Choi, H.S., Meier, D., 2013. Fast pyrolysis of kraft lignin-vapor cracking over various fixed-bed catalysts. J. Anal. Appl. Pyrol. 100, 207-212.

[11] Danalatos, N.G., Archontoulis, S.V., 2010. Growth and biomass productivity of kenaf [Hibiscus cannabinus L.] under different agricultural inputs and management practices in central Greece. Ind. Crops Prod. 32, 231-240.

[12] Fidalgo, M.L., Terron, M.C., Martinez, A.T., Gonzalez, A.E., GonzalezVila, F.J., Galletti, G.C., 1993. Comparative study of fraction from alkaline extraction of wheat straw through chemical degradation, analytical pyrolysis, and spectroscopic technology. J. Agric. Food Chem. 41, 1621-1626.

[13] Gai, C., Dong, Y., Zhang, T., 2013. The kinetic analysis of the pyrolysis of agricultural residue under non-isothermal conditions. Bioresour. Technol. 127, 298-305.

[14] Gooty, A.T., Li D., Berruti, F., Briens C., 2014. Kraft-lignin pyrolysis and fractional condensation of its bio-oil vapors. J. Anal. Appl. Pyrol. $106,33-40$

[15] Guo, X., Liu, Z., Liu, Q., Shi, L., 2015. Modeling of kraft lignin pyrolysis based on bond dissociation and fragment coupling. Fuel Process. Technol. 135, 133-149.

[16] Gutiérrez, A., Rodríguez, I.M., Río, J.C., 2004. Chemical characterization of lignin and lipid fractions in Kenaf bast fibers used for manufacturing high-quality papers. J. Agric. Food Chem. 52, 4764-4773.

[17] Hemmasi, A. H., 2012. Producing Paper from Iranian Kenaf by Soda and Soda-Anthraquinone Processes. American-Eurasian J. Agric. Environ. Sci. 12, 886-889.

[18] Huang, Y., Wei, Z., Qju, Z., Yin, X., Wu, C., 2012. Study on structure and pyrolysis behavior of lignin derived from corncob acid hydrolysis residue. J. Anal. Appl. Pyrol. 93, 153-159.

[19] Jiang, G., Nowakowski. D.J., Bridgwater, A., 2010. Effect of the temperature on the composition of lignin pyrolysis products. Energy Fuels. 24, 4470-4475.
[20] Jiang, G., Nowakowski, D.J., Bridgwater, A.A, 2010. Systematic study of the kinetics of lignin pyrolysis. Thermochimi. Acta. 498 61-66.

[21] Jin, G., Nakagawa-izumi, A., Shimizu, K., Ohi, H., 2006. Chemical characterization and kraft pulping response of Hibiscus cannabinus bast. J. Wood Sci. 52, 107-112.

[22] Kato, Y., Kohnosu, T., Enomoto, R., Akazawa, M., Yoon, S.L. Kojima, Y., 2014. Chemical properties of bio-oils produced by fas pyrolysis of bamboo. Trans. Mat. Res. Soc. Japan. 39, 491-498.

[23] Khristova, P., Kordsachia, O., Patt, R., Khider, T., Karrar, I., 2002 Alkaline pulping with additives of kenaf from Sudan. Ind. Crops Prod. 15, 229-235.

[24] Li, L., Zhang, H., Zhuang, X., 2005. Pyrolysis of waste paper: characterization and composition of pyrolysis oil. Energy Sources. $27,867-873$

[25] Lopez-Velazquez, M.A., Santes, V., Balmaseda, J., Torres-Garcia, E., 2013. Pyrolysis of orange waste: A thermo-kinetic study. J. Anal. Appl. Pyrol. 99, 170-177.

[26] Lou, R. Wu, S.B., Gao, J.L., 2010. Effect of condition on fast pyrolysis of bamboo lignin. J. Anal. Appl. Pyrol. 89, 191-196.

[27] Lou, R., Wu, S.B., 2011. Product properties from fast pyrolysis of enzymatic/mild acidolysis lignin. Appl. Energ. 88, 316-322.

[28] McLaughlin, S.B., Bouton, J., Bransby, D., Conger, B.V., Ocumpaugh, W.R., Parrish, D.J., Taliaferro, C., Voge, K.P.l., Wullschleger, S.D., 1999. Developing switch grass as a bioenergy crop, in: Janick, J. (Ed.), Perspectives on new crops and new uses. ASHS Press, Alexandria, VA, pp. 282-299.

[29] Nishimura, N., Izumi, A., Kuroda, K., 2002. Structural characterization of kenaf lignin: differences among kenaf varieties. Ind. Crops Prod. 15, 115-122

[30] Ohtani, Y., Mazumder, B.B., Samejima, K., 2001. Influence of the chemical composition of kenaf bast and core on the alkaline pulping response. J. Wood Sci. 47, 30-35.

[31] Patwardhan, P.R., Satrio, J.A., Brown, R.C., Shanks, B.H., 2009 Product distribution from fast pyrolysis of glucose-based carbohydrates. J. Anal. Appl. Pyrol. 86, 323-330.

[32] Ronsee, F., Bai, X., Prins, W., Brown, R.C., 2012. Secondary reactions of levoglucosan and char in the fast pyrolysis of cellulose Environ. Prog. Sustainable Energy. 31, 256-260.

[33] Seca, A.M.L., Cavaleiro, J.A.S., Domingues, F.M.J., Silvestre, A.J.D., Evtuguin, D., Neto, C.P., 1998. Structural characterization of the bark and core lignins from kenaf (Hibiscus cannabinus). J Agric. Food Chem. 46, 3100-3108.

[34] Shra'ah, A.A, Helleur, R., 2014. Microwave pyrolysis of cellulose at low temperature. J. Anal. Appl. Pyrol. 105, 91-99.

[35] Temiz, A., Akbas, S., Panov, D., Terziev, N., Alma, S.P., Kose, G. 2013. Chemical composition and Efficiency of bio-oil obtained from giant cane (Arundo donax L.) as a wood preservative. Bioresouces. 8, 2084-2098.

[36] Vinu, R., Broadbelt, L.J., 2012. A mechanistic model of fast pyrolysis of glucose-based carbohydrates to predict bio-oil composition. Energy Environ. Sci. 5, 9808-9826.

[37] Wang, K., Brown, R.C., Homsy, S., Martinez, L., Sidhu, S.S., 2013 Fast pyrolysis of microalgae remnants in a fluidized bed reactor for bio-oil and biochar production. Bioresour. Technol. 127, 494-499.

[38] Ye, Y., Fan, J., Chang, J., 2012. Effect of reaction conditions on hydrothermal degradation of cornstalk lignin. J. Anal. Appl. Pyrol. 94, 190-195.

[39] Yang, H., Tan, R., Chen, H., Zheng, C., Lee, D.H., Liang, D.T., 2006. In-depth investigation of biomass pyrolysis based on three major components: hemicellulose, cellulose and lignin. Energy Fuel. 20,388-393.

[40] Zhang, Q., Chang, J., Wang, T.J., Xu, Y., 2007. Review of biomass pyrolysis oil properties and upgrading research. Energy Convers. Manage. 48, 87-92. 